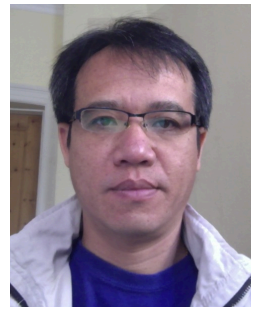

Sithong Thongmanivong

Faculty of Forestry

National University of Laos

\title{
HOW LAOS IS MOVING FORWARD WITH REDD+ SCHEMES
}

\author{
Khamla Phanvilay \\ Faculty of Forestry \\ National University of Laos \\ Thoumthone Vongvisouk \\ Department of Geoscience \& \\ Natural Resource Management \\ Faculty of Science \\ University of Copenhagen
}
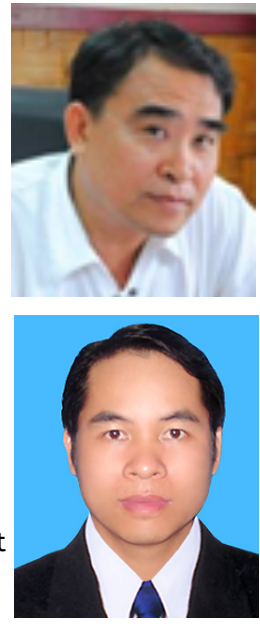

The forest cover in Laos has decreased over the past three decades for variety of reasons. The current Laos Government has committed itself to restoring the forest cover to 70 per cent by 2020. As a result, many conservation projects and programs have been planned and implemented in different parts of the country. REDD+ was introduced in late 2007; however, progress of implementation of REDD+ has been slow. This paper examines and updates the status of REDD+ implementation in Laos, using information from literature and interviews with relevant individuals. The paper reveals that progress of REDD+ is slow not only due to external factors but also on internal factors. Currently, there are various international organisations and NGOs, from both the public and private sectors, attempting to pilot REDD+ projects. Laos faces many challenges in implementing REDD+, including institutional arrangements; appropriate methods for carbon accounting, reporting and verification; benefit sharing; and engaging local communities.

\section{Introduction}

Laos is one of the few countries in Southeast Asia that still has close to 50 per cent of its land under forests. In the 1960s, the country's forests covered 70 per cent of Laos' land area. By 2010, this cover had declined to 41 per cent. ${ }^{1}$ There are various drivers of forest cover loss in Laos, including infrastructure development, hydropower development and the conversion of forests to cash crops and industrial tree plantations. Also significant are 'slash and burn' cultivation methods: about 80 per cent of the country's population live in rural areas and engage in such agricultural practices.

Reducing Emission from Deforestation and Forest Degradation (REDD) is a program that could help to reduce further forest destruction in Laos. REDD is an effort to create a financial value for the carbon stored in forests, offering incentives for developing countries to reduce emissions from forested lands and invest in low-carbon paths to sustainable development. REDD+ goes beyond targeting deforestation and forest degradation and includes a focus on the role of conservation, sustainable management of forests and enhancement of forest carbon stocks. ${ }^{2}$

The Lao Government has been participating in the international REDD negotiation process since 2007. Recently, the participation of Lao Government has extended to involvement in multilateral negotiating blocs, such as ASEAN, G-7 and China, and Least Developed Countries (LDC) group, to advance agreement on REDD. ${ }^{3}$ Laos' Climate Change Strategy, National Socio-Economic Development Plan 2011-15, the Agricultural Development

\footnotetext{
1 MAF, 'Annual Review of REDD+ Activities in Lao PDR' (Department of Forestry, Ministry of Agriculture and Forestry, Vientiane, LAO PDR, 2011a).

2 UN-REDD Program, About REDD+ <http://www.un-redd.org/aboutredd/tabid/582/default.aspx>.

${ }^{3}$ DOF, 'Lao PDR Preliminary Proposal for FIP' (Department of Forestry, Ministry of Agriculture and Forestry, Vientiane, 2011).
} 
Strategy 2011-20 and the Agricultural Master Plan 2011-15 all indicate Laos' interest in carbon market mechanisms and REDD+. The forestry and land-use sector have been identified as the largest greenhouse gas emitters in Laos but hold also the largest mitigation potential while simultaneously promising environmental and socioeconomic benefits. ${ }^{4}$ Laos is in a good position to capture benefits from the global REDD+ mechanisms. The country ranks $12^{\text {th }}$ among the top 20 tropical countries with high carbon storage potential, estimated to be between 530 and 1000 million tons of $\mathrm{CO}_{2}$ from 1990 to 2050.

The country's greenhouse gas (GHG) emissions come from four main sectors: the forestry industry is the greatest source of emissions (71\%), followed by agriculture (24\%), energy production (4\%) and environment $(1 \%) .^{5}$

In 2000, the Lao Government committed itself to restoring the country's forest cover to 70 per cent by $2020 .^{6}$ The REDD+ mechanisms is likely to contribute meaningfully to enabling this commitment to be achieved. Laos aims to use market-based and incentive mechanisms in the short-term, as well encouraging participation in the voluntary market; but will use compliance measures in the longer-term once international protocols have been agreed. $^{7}$

\section{REDD+ and readiness preparation}

In 2007, the Lao Government joined the Forest Carbon Partnership Facility (FCPF) with Official Notice No. 1896/SCG, appointing the Ministry of Agriculture and Forestry (MAF) to be the Country's national representative. $^{8}$ The FCPF is a World Bank program aimed at assisting developing countries to reduce emissions from deforestation and forest degradation. The FCPF was launched at the $13^{\text {th }}$ session of the Conference of the Parties (COP) to the United Nations Framework Convention on Climate Change (UNFCCC) in Bali and became operational in June 2008.

In 2008, MAF established a national committee called 'The REDD+ Task Force', chaired by the Director General of the Department of Forestry (DOF), to deal with REDD-related issues in Laos. Four years later, through a Ministerial Decree, ${ }^{9}$ the Task Force was expanded to include 15 members from various public sector institutions: (i) DOF under MAF, (ii) the Department of Forest Inspection (DOFI) under MAF, (iii) the Land Use and Development Department under the National Land Management Authority (NLMA), (iv) the Department of Environment (DOE) under the Water Resource and Environment Administration (WREA), (v) the National Agriculture and Forestry Research Institute (NAFRI), (vi) the Faculty of Forestry (FOF) at the National University of Laos (NUOL), (vii) the Mining Department (DOM) under the Ministry of Energy and Mines (MEM), (viii) Electricity Department under MEM, (ix) the Law Department under the Ministry of Justice, (x) the Planning Department under the Ministry of Planning and Investment (MPI), (xi) the International Finance Cooperation Division under the Ministry of Finance (MOF), (xii) the Lao National Front (Ethnic Groups) (xiii) the Lao Women's Union, (xiv) the Lao Front for National Construction, and (xv) the Lao National Chamber of Industry and Commerce.

The REDD+ Task Force submitted its Readiness Preparation Proposal (R-PP) to the World Bank in 2010. The proposal was accepted in 2011 and is awaiting financial support from the World Bank for implementation of the FCPF. However, the recent restructuring of the government's administration for the forestry sector has impacted on REDD+ preparation and implementation. Responsibility for the conservation and protection of forests have been transferred to the Ministry of Natural Resources and Environment (MONRE), while responsibility for productive forest and small-scale forest investment, including village forests, are under the MAF. This new administrative structure is delaying the processes of REDD+ implementation.

In parallel with the REDD+ R-PP, the Lao Government also cooperates with various international funding organisations and REDD+ related projects. These include: Climate Protection Through Avoided Deforestation $(\text { CliPAD })^{10}$; Participatory Land Use and Forest Management for Reducing Deforestation in Laos (PAREDD); ${ }^{11}$ REDD

${ }^{4}$ DOF, 'Forest Carbon Partnership Facility Readiness Preparation Proposal’ ('RPP') (Department of Forestry, Ministry of Agriculture and Forestry, Vientiane, LAO PDR 2010).

${ }^{5} \mathrm{MAF}$, above $\mathrm{n} 1$.

${ }^{6}$ PMO, 'Forestry Strategy to the Year 2020 of the Lao PDR' (Prime Minister's Office, Vientiane, Lao PDR 2005)

${ }^{7}$ DOF, above n 4 .

8 Ibid.

9 MAF, 'Minister Decision on Establishing a Task Force Committee for the Implementation of REDD Activities' (Ministry of Agriculture and Forestry, Vientiane, Lao PDR, 2011(b)).

${ }^{10}$ MAF, 'Climate Protection through Avoided Deforestation (CliPAD) TC Module' (Project No: 2008.2045.6, June 2010) <http://www.theredddesk.org/sites/default/files/technical_cooperation_module_clipad2_0.pdf>.

${ }^{11}$ MAF and Japan International Cooperation Agency, 'Participatory Land Use and Forest Management for Reducing Deforestation in Lao PDR (PAREDD)' (Project Document, January 2010)

<http://www.theredddesk.org/sites/default/files/110914_paredd_pd_final_1.pdf>. 
components of the Sustainable Forestry and Rural Development Project (SUFORD); Forestry Sector Capacity Development Project (FSCAP); Lowering Emissions from Asia's Forests (LEAF) project; Forest Information Management (FIM) Program; Forest Preservation Program (FPP); as well as the Forest Investment Program (FIP). In addition, private sector organisations, such as New Jip Cheng, a subsidiary of Honda, and a Vietnamese (Truong Son) company have approached to the Lao Government for permission to conduct feasibility studies for participation in REDD+ in Laos.

\section{Options and challenges of REDD+ in Laos}

The Lao Government has decided to follow a nested approach for the implementation of REDD+. ${ }^{12}$ This approach will include REDD+ projects developed by private and/or NGO actors of sub-national jurisdictional REDD+ schemes. Currently the national strategies and institutional arrangements have been developed, and related laws and regulations have been revised, especially the forestry law and natural resource laws. ${ }^{13}$ Under the R-PP schedule, a Measurement, Reporting and Verification (MRV) system for REDD+, which intends to capture performance of individual provinces and nested project-level activities into the national results, is being developed by the REDD+ Task Force.

A jurisdictional MRV system is considered to be more desirable than a project-based MRV system. Although a jurisdictional MRV system requires a great deal of inputs in terms of infrastructure investment, technical assistance and capacity building at the sub-national level, it should lead to a more structured and flexible context, allowing for the satisfaction of both national and external interests in REDD+ activity development. CliPAD and PAREDD intend to use the jurisdictional crediting system once there has been an accumulation of experience with the initial REDD+ projects in Laos. There is recognition by the Lao Government that the REDD+ implementation requires complex institutions and institutional mechanisms. In order to facilitate the institutional building process, Laos intends to follow emerging internationally recognised standards for jurisdictional, project-level accounting and social and environmental safeguards.

Currently pilot REDD+ projects have been initiated in Laos, with international support. They are based in conservation areas and focus only on stopping deforestation. The benefit sharing mechanisms of the pilot project for local communities are not yet clear. It is envisaged that it will be difficult to inspire local people to participate in the projects, making it difficult for the projects to achieve increased carbon stocks in the target project areas.

Overall, although Laos has progressed on REDD+ preparation, the Lao Government still faces significant difficulties with REDD+ implementation. The Lao Government lacks confidence to move on expressions of interest because of the lack of clarity of the international REDD + framework and the lack of readiness of the Laos' legal framework. Thus far, the main activities in relation to REDD+ in Laos have been focused on institutional and capacity building, and revision of forest and related laws. The National Land Policy (NLP) is being developed to become the country's natural resource management and administration master plan. The NLP is scheduled for approval by the Lao Government National Assembly in June 2013.

A new forest classification system is also being developed which categorises land use and land cover types, and reports on the technical aspect of image processing capability for mapping and field monitoring. Currently, Laos does not have a REDD+ strategy or a MRV system. The national MRV system and most other technical strategies have been developed only to the concept stage while institutional and ministerial rearrangements are underway. The R-PP is a roadmap policy document for Laos and provides basic guidelines for the development of MRV approaches. However, it leaves several technical and conceptual areas for further study.

The restructure of the government's forest sector's administration has impacted on REDD+ preparation and implementation. Management of the forest sector is now under two ministries, each with their own terms of reference with regards to the responsibility of forest management according to the different national forest categories.

In addition to challenges in REDD+ mentioned above, the harvesting of natural resources is the main source of economic income to the nation. The Lao Government's decision to exploit natural resources to generate economic development and increase Gross Domestic Product (GDP) contradicts efforts to implement REDD+ related activities.

\footnotetext{
${ }^{12}$ DOF, above $\mathrm{n} 4$.

${ }^{13}$ The REDD Desk, REDD Countries <http://www.theredddesk.org/countries/laos/legal_framework>.
} 


\section{Issues to be further explored for REDD+ in Laos}

Although the REDD+ Task Force has shared information and consulted with the institutional and stakeholders since 2010, the following items remain unclear and still need for further elaboration:

1. Basic information on REDD+: What are the issues being negotiated internationally and what are the implications of these at the national level? What are the incentives from implementing REDD+? How will these be shared? What are the ways for Laos to engage in a REDD+ mechanism? What benefits could be available to different stakeholders?

2. Land use rights and land tenure systems: What are the potential implications of REDD+ within the existing legal context on land use and land tenure in Laos?

3. Forest Governance: How can REDD+ support existing initiatives in forest governance and forest law enforcement? How can REDD+ deal with ill-considered allocations of land for concessions and illegal logging? How can REDD+ deal with drivers of deforestation and forest degradation?

4. Benefit sharing and distribution systems: Evaluation of existing benefit sharing systems is needed to determine if REDD + could make use of any existing agreements, assess what systems of benefit sharing could be appropriate and provide maximum benefits.

5. Reference Emission Level (REL) and MRV systems: How can REL be defined? What are the implications of various approaches for defining RELs on the expected future benefits? What methodologies are used for MRV? What are the roles and responsibilities of different stakeholders in MRV?

6. Potential REDD+ projects and activities: How can REDD+ activities be distributed or implemented in the entire landscapes of the country to ensure that all stakeholders (including deforestation drivers) of different forest management regimes (production forest, protection forest, conservation forests, community managed forest, plantations) are involved?

\section{Conclusion}

Implementing REDD+ in Laos still has many hurdles to overcome. The challenges have been made harder because international commitment, especially in the latest COP-18 meeting in Doha, has not reached concrete consensus. The Lao REDD+ initiative struggles to cope with the significant number of international and bilateral technical cooperation projects being offered. Preparing for REDD+ readiness requires not only attention to the Laos forestry sector, but also to ensuring that the public and other key stakeholders understand REDD proposals and coordinate their activities accordingly. Measures to protect forests from further degradation and destruction need to be applied as a means for economic development. A significant concern is that government decisions are being made to exploit natural resources to generate economic development and increase GDP. These moves often contradict the current REDD+ movement. Furthermore, changed public sector institutional arrangement are significantly delaying REDD+ related activities in Laos. The new ministry still lacks the resources (mainly staff and capacity) to progress REDD+. 